Cornell University Law School

Scholarship@Cornell Law: A Digital Repository

7-19-2021

A Detailed Assessment of the Sexual Assault Prevalence Statistics at the Center of the Military Justice Reform Movement

Brian L. Cox

Follow this and additional works at: https://scholarship.law.cornell.edu/clsops_papers

Part of the Criminal Law Commons, and the Military, War, and Peace Commons 


\title{
A Detailed Assessment of the Sexual Assault Prevalence Statistics at the Center of the Military Justice Reform Movement
}

\section{Contents}

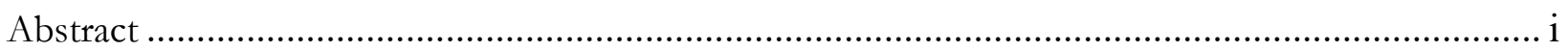

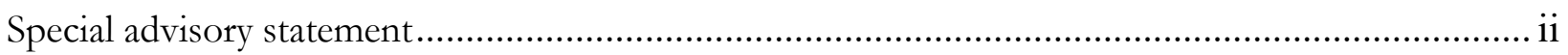

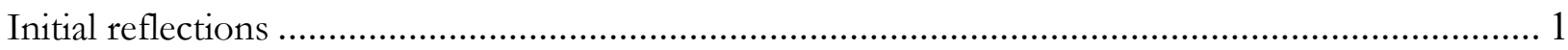

Describing the Context for the Central Prevalence Statistics ............................................................. 3

Methodological Observations Relevant to the WGRA Prevalence Estimate ...................................... 5

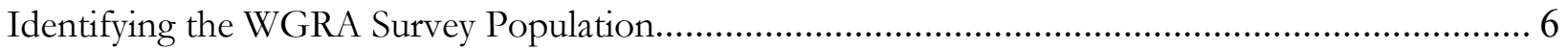

WGRA Report Limitation: “Behaviors Endorsed By Respondents' Self-Reports” ............................ 7

WGRA Report Limitation: "Unique Military Context".................................................................... 11

WGRA Report Limitation: Non-Response Bias ......................................................................... 13

The Way Ahead with WGRA Statistics Situated in the Proper Context ......................................... 14

\begin{abstract}
"Twenty thousand service members experience sexual assault every year" while "only a tiny fraction of those end up with any kind of action at all in the military justice system." Lynn Rosenthal, director of the DoD Independent Review Commission, recently offered this observation at a press conference while summarizing the findings reflected in the commission's report. Senator Kirsten Gillibrand indicated in a recent blog post that "an estimated 20,500 service members are sexually assaulted every year" to make the case that there "is an epidemic of sexual assault in the military and the current military justice system has proven incapable of addressing it." Likewise, General Mark Milley, currently the Chairman of the Joint Chiefs of Staff, recently observed, "If we had 20,000 casualties in Afghanistan last year or 20,000 casualties in Iraq, we'd be taking some pretty radical actions to correct that."

The assertion that an estimated 20,000 U.S. military service members are sexually assaulted each year has become a common refrain in contemporary discourse. Indeed, the estimated prevalence data have long been at the center of the movement to divest commanders of the authority to initiate criminal charges and refer offenses to court-martial. Whence is this estimate of 20,000 annual sexual assaults drawn, and how effective is it as a measure of the performance of the commander-centric U.S. military justice system?

This essay conducts a detailed assessment of the claim that an estimated 20,000 service members are sexually assaulted each year. The source of the assertion, a biennial survey that was last conducted by the DoD Office of People Analytics in 2018, is identified along with prior iterations of the survey. With the source identified, the essay examines several limitations that support the conclusions that the "estimate" is not an accurate approximation for actual sexual assault offenses and that these central prevalence data are not an effective measure of the performance of the U.S. military justice system. After examining these factors in detail, the essay concludes by considering the landscape of the debate regarding commander disposition authority when the prevalence data at the center of the reform movement are put into proper context.
\end{abstract}




\section{Special advisory statement:}

This essay engages with and describes content that readers who have experienced sexual trauma may find to be distressing. While specific details regarding experiences of sexual trauma are not described, certain aspects of sexual assault crimes are described in detail. This is particularly the case on pages 8 to 11 of the essay, which describe factors involved with the crimes of rape, sexual assault, and abusive sexual contact. If you have, or if someone close to you has, experienced such offenses, some material in the essay may be distressing for you.

As someone who has personally experienced sexual assault while in the military, I can directly relate to some of the challenges associated with engaging with material of this nature. My own experience occurred soon after arriving at my first duty assignment - 3/504 PIR, 82nd Airborne Division at Fort Bragg, North Carolina - in August 1996. Based on the particular circumstances of my own experience, I was and have been able to cope well and move on afterward. I recognize that not everyone who has experienced sexual trauma is able to do so. For some readers who have experienced sexual trauma, developing a support plan prior to reading this essay may be advisable.

Another aspect of this essay that a reader who has experienced sexual trauma, particularly in the military context, may find distressing is that the analysis challenges a central mode of discourse that has emerged involving sexual assault in the military. In this essay, I directly challenge the manner in which prevalence estimates have been used to describe an "epidemic of rape and sexual assault" that ostensibly has long beset the U.S. military and that the commandercentric military justice system has been unable to alleviate. In challenging the use of prevalence data that has long formed the basis of this characterization, I do not intend to suggest that sexual assault does not occur in the military or that there is no room for the military to improve in relation to the prevention of and response to sexual assault.

I stand together, shoulder to shoulder, with those who have experienced sexual assault in the military and with those who demand improved performance in relation to the prevention of and response to military sexual trauma. As a retired service member and former military prosecutor, part of what that commitment means for me is achieving a more informed understanding of the exact nature of the problem that needs to be addressed. Only in this way will we be able to identify, develop, and implement measures that will be truly effective. This is an enduring personal effort, even though the specific subject matter of this essay is limited to the manner in which prevalence data have been used as a measure of the effectiveness of the military justice system. Challenging the manner in which prevalence data have been utilized, though, is not intended to suggest that sexual assault does not occur in the military or that there is nothing that needs to be done to improve performance related to the prevention of and response to sexual assault in the military. 


\section{A Detailed Assessment of the Sexual Assault Prevalence Statistics at the Center of the Military Justice Reform Movement}

\section{by Brian L. Cox*}

The current session of Congress has ushered in a number of significant developments in the long-running debate involving the role of the military commander in deciding whether to adjudicate alleged offenses related to sexual assault. For the first time, Senator Kirsten Gillibrand reports that a bill $^{1}$ she and a number of co-sponsors have introduced in the Senate currently has a "filibuster-proof majority." "In a related development, Lloyd Austin is the first Secretary of Defense to endorse a measure that would divest commanders of disposition authority for sexual assault and "related crimes" such as domestic violence, ${ }^{3}$ and President Joe Biden has since adopted Secretary Austin's recommendation. ${ }^{4}$ The endorsements by Secretary Austin and President Biden follow a report published by the DoD Independent Review Commission (IRC), which is the first official report to recommend divesting disposition authority from commanders - at least for alleged sexual assault and related offenses. ${ }^{5}$

\footnotetext{
* (C) 2021. Adjunct professor of law and matriculating J.S.D. candidate, Cornell Law School; visiting scholar, Queen's Law in Ontario. In 2018, Prof. Cox retired from the U.S. Army after 22 years of military service. While in the military, Prof. Cox served as an airborne infantry soldier, combat camera operator, airborne infantry officer, and for seven years as an Army judge advocate. His combat deployments include Iraq from 2003-2004 as a combat camera operator and Afghanistan from 2013-2014 as an operational law advisor and then chief of international and operational law for Regional Command-East. Prof. Cox also served as a military prosecutor, federal prosecutor, brigade judge advocate, administrative law attorney, legal assistance attorney, and military magistrate while he was a judge advocate. As an Army judge advocate, Prof. Cox completed the Special Victims Unit Investigations Course at the U.S. Army Military Police School as well as the Intermediate Trial Advocacy Course and the Brigade Leader's Course at the U.S. Army Judge Advocate General's Legal Center and School, among other professional certification courses.
}

${ }^{1}$ Military Justice Improvement and Increasing Prevention Act of 2021, S. 1520, 117th Cong. (2021), https://www.congress.gov/bill/117th-congress/senate-bill/1520.

${ }^{2}$ See Jordain Carney, Democrats Wage High-profile Fight Over Military Sexual Assault, THE HILl (June 2, 2021), https://thehill.com/policy/defense/556390-democrats-wage-high-profile-fight-over-military-sexual-assault (reporting that Gillibrand has indicated that supporters "have a bipartisan, filibuster-proof majority backing this bill").

${ }^{3}$ See Memorandum, Sec'y Def., Department of Defense Actions and Implementation Guidance to Address Sexual Assault and Sexual Harassment in the Military (July 2, 2021), https://www.defense.gov/Explore/Spotlight/Independent-Review-Commission-on-Sexual-Assault-in-the-Military. ${ }^{4}$ See Press Release, Statement of President Joe Biden on the Results of the Independent Review Commission on Military Sexual Assault (July 2, 2021), https://www.whitehouse.gov/briefing-room/statementsreleases/2021/07/02/statement-of-president-joe-biden-on-the-results-of-the-independent-review-commission-onmilitary-sexual-assault.

${ }^{5}$ See HARD TRUTHS AND THE DUTY TO CHANGE: RECOMMENDATIONS FROM THE INDEPENDENT REVIEW COMMISSION ON SEXUAL ASSAUlT IN THE MilitaRY (2021), https://media.defense.gov/2021/Jul/02/2002755437/-1/1/0/irc-full-report-final-1923-7-1-21.pdf/irc-full-report-final-1923-7-1-21.pdf. 
The merits of the proposed measure to divest commanders of disposition authority for allegations of sexual misconduct have been debated at length over the years. ${ }^{6}$ While I have my own views involving the merits of the measure based on my experience as a (now retired) Army judge advocate, the goal of the present essay is not to debate the merits. Nor is my intent here to conduct a critical assessment of the IRC report that persuaded Secretary Austin and President Biden to endorse the recommendation to shift disposition authority to military lawyers for certain offenses though I am currently engaged in a detailed study of the report.

My intent with this essay is to examine an aspect of the debate that has thus far not been explored in great detail in prior scholarship on the topic. At the very core of the debate involving disposition authority for commanders is that the military has for too long experienced what is described as an "epidemic of rape and sexual assault" that has not been alleviated by prior measures to improve the problem. This essay conducts an in-depth assessment of the prevalence statistics that form the basis of the characterization that the military has long experienced an epidemic of rape and sexual assault.

As lawmakers get set to revise and debate the legislation that is currently pending in both chambers, enhanced clarity involving the precise problem they are seeking to address is vitally important in making informed decisions. To lend structure to the present examination, the analysis seeks to answer two central questions: 1) How accurate are the central prevalence statistics as a measure of actual sexual assault offenses?; and 2) What do the central prevalence statistics reveal about the performance of the military justice system when applied to the number of cases referred by commanders to court-martial each year?

As the analysis below reveals, the central prevalence statistics do not present an accurate approximation for the actual number of sexual assault offenses in the military each year, and,

\footnotetext{
${ }^{6}$ See, e.g., Rachel VanLandingham, Professional Criminal Prosecution Versus the Siren Song of Command: The Road to Improve Military Justice, JUST SECURITY (June 21, 2021), https://www.justsecurity.org/77025/professionalcriminal-prosecution-versus-the-siren-song-of-command-the-road-to-improve-military-justice; Charlie Dunlap, Don't Hobble the Military Justice Authority and Responsibility of America's Commanders, LAWFIRE (June 1, 2021), https://sites.duke.edu/lawfire/2021/06/01/dont-hobble-the-military-justice-authority-and-responsibility-of-americascommanders; Geoffrey S. Corn, Chris Jenks \& Timothy C. MacDonnell, A Solution in Search of a Problem: The Dangerous Invalidity of Divesting Military Commanders of Disposition Authority for Military Criminal Offenses, JUST SECURITY (June 29, 2020), https://www.justsecurity.org/71111/introducing-an-open-letter-from-former-u-smilitary-commanders-judge-advocates-commander-authority-to-administer-the-ucmj; Eugene R. Fidell, Military Justice Reform, the 2020 Pledge, and the President's Power, JusT SECURITY (Feb. 14, 2020), https://www.justsecurity.org/68672/military-justice-reform-the-2020-pledge-and-the-presidents-power; Jordan Stapley \& Geoffrey Corn, Military Justice Reform: The 'Be Careful What You Ask For' Act, MiLITARY Times (June 2, 2021), https://www.militarytimes.com/opinion/commentary/2021/06/02/military-justice-reform-the-be-carefulwhat-you-ask-for-act.
} 
partially as a result, the numbers reveal very little about the current performance of the commandercentric system of disposition authority. The analysis begins by putting the prevalence statistics in context before closely examining the source of the statistics.

\section{Describing the Context for the Central Prevalence Statistics}

Senator Gillibrand summarizes well in a recent blog post the central prevalence statistics that form the core of her long-running drive to divest commanders of court-martial convening authority. ${ }^{7}$ She begins the post by asserting that there "is an epidemic of sexual assault in the military and the current military justice system has proven incapable of addressing it." In support of this assertion, Senator Gillibrand notes that "an estimated 20,500 service members are sexually assaulted every year, but last year, fewer than 6,300 of those service members reported their assaults." To apply the prevalence statistics to the performance of the military justice system, Senator Gillibrand notes that "less than one in ten of the cases considered are sent to trial, and just a small fraction of those cases end in conviction."

The solution to this problem, according to Senator Gillibrand, is "to change who is responsible for handling these cases" since "commanders are also not trained lawyers." Senator Gillibrand makes the case that even though military commanders say they have the solutions, by her estimation they "don't have it" because "by nearly every measure things are moving in the wrong direction." Senator Gillibrand concludes the post by asserting that the draft legislation should be adopted because it "would help us deliver on our national promise of justice for all."

Senator Gillibrand makes several points in the post that warrant further scrutiny, but the focus of this essay is the very first thread in the tapestry she describes in support of the measure. That is, that the military experiences an "epidemic of sexual assault" since an "estimated 20,500 service members are sexually assaulted each year." With a current total active-duty end strength of just over 1.3 million service members, ${ }^{8}$ a condition by which over $1.5 \%$ of the force is sexually assaulted each year would certainly qualify as an epidemic in need of drastic measures to correct.

\footnotetext{
${ }^{7}$ See Kirsten Gillibrand, Sen. Gillibrand: Voters Want Lawyers - Not Commanders - To Prosecute Sexual Assault In The Military, DATA FOR PROGRESS (July 12, 2021), https://www.dataforprogress.org/blog/2021/7/12/voters-wantlawyers-not-commanders-prosecuting-sexual-assault.

${ }^{8}$ Dep't Def., Armed Forces Strength Figures for May 31, 2021 (pdf download), https://dwp.dmdc.osd.mil/dwp/api/download?fileName=ms0_2105.pdf\&groupName=milTop.
} 
This estimate that around 20,000 service members experience sexual assault each year has become a staple in discourse involving the role of the commander in deciding whether to adjudicate alleged sexual assault offenses. A current page on Senator Tammy Baldwin's website, for example, claims that "almost 21,000 service members were sexually assaulted in 2018 despite repeated efforts to end [the] scourge of sexual harassment and assault in the military." ${ }^{\text {"9 }}$ Representative Jackie Speier, a long-time advocate of the proposed change, recently opened a press conference in support of the House version of the draft legislation by asserting, "We're here today because each year 20,000 service members are sexually assaulted."10

Lynn Rosenthal, director of the DoD Independent Review Commission, asserted in a recent Pentagon briefing at which she announced the IRC recommendations that "twenty thousand service members experience sexual assault every year" while "only a tiny fraction of those end up with any kind of action at all in the military justice system." ${ }^{11}$ Likewise, a recent video op-ed posted by The New York Times flashes the number "20,500” on the screen to accompany an explanation by Colonel (ret.) Don Christensen, president of the advocacy group Protect Our Defenders, claiming that "thousands of service members report being raped or sexually assaulted each year, but only a fraction of those cases (the screen now displays the number $0.5 \%$ ) result in a conviction." 12 Similarly, a recent news report observes that a DoD biennial survey "found that more than 20,000 service members said they experienced some type of sexual assault, but only a third of those filed a formal report." 13

What was accurately described by Senator Gillibrand as an estimate of 20,000 sexual assaults in the military each year, then, is often treated in discourse as an actual number of sexual assaults. When it is treated as an actual number of offenses, the outcome can be quite startling indeed. As what is described by Protect Our Defenders as a "fact sheet" from 2015 points out, "the sexual

\footnotetext{
${ }^{9}$ Press Release, Tammy Baldwin, Senator Baldwin Supports the of New, Bipartisan Military Justice Improvement And Increasing Prevention Act (April 30, 2021), https://www.baldwin.senate.gov/press-releases/military-justiceimprovement-and-increasing-prevention-act-2021.

${ }^{10}$ See Kennedy Sessions, Lawmakers Introduce the Vanessa Guillen Act into Congress, TeXAS SignaL (June 24, 2021), https://texassignal.com/lawmakers-introduce-the-vanessa-guillen-act-into-congress.

${ }^{11}$ See Dep’t Def., Pentagon Press Secretary John F. Kirby Holds a Press Briefing (July 2, 2021), https://www.defense.gov/newsroom/transcripts/transcript/article/2681883/pentagon-press-secretary-john-f-kirbyholds-a-press-briefing.

${ }^{12}$ Joni Ernst, Don Christensen \& Mei-Ling Jerez, There's a Sexual Assault Crisis in the Military. Congress Can Stop It, N.Y. TIMES (June 1, 2021), https://www.nytimes.com/video/opinion/100000007737321/sexual-assaultmilitary-ernst-gillibrand.html.

${ }^{13}$ Robert Burns, Top General Drops Opposition to Change in Sex Assault Policy, Associated Press (May 3, 2021), https://apnews.com/article/government-and-politics-e343b149e17bfa5cc104ea354bdf8065.
} 
assault rate remains the same as 2010."14 If this estimate of about 20,000 actual offenses each year dating back to at least 2010 is accurate, it is quite reasonable to conclude that no previous measures have been effective at alleviating the "epidemic" of sexual assault.

With such an apparently shocking and long-running statistical prevalence of sexual assault in the military, it is of vital importance to fully understand how this statistic is derived and what it suggests about the effort to prevent and respond to sexual assault in the military. The following sections explore the central prevalence statistics in detail. The essay then concludes with some reflections on the way ahead regarding the present debate with the sexual assault prevalence statistics situated in proper context.

\section{Methodological Observations Relevant to the WGRA Prevalence Estimate}

In short, the suggestion that approximately 20,000 sexual assaults occur in the military annually is drawn from a report that analyzes responses to a biennial survey that is currently administered by the DoD Office of People Analytics. Though the report has been known by other names in the past, the current nomenclature for the report is Workplace and Gender Relations Survey of Active Duty Members (WGRA). The most recent WGRA report, which analyzes the 2018 version of the biennial survey, estimates that 12,927 women and 7,546 men reportedly experienced a sexual assault in the past 12 months. ${ }^{15}$ This estimated sum is 20,473 - or about 20,500 .

By way of comparison, the total estimated number of military personnel who reported experiencing sexual assault in the previous 12 months for the 2016 version of the survey is $14,881 .{ }^{16}$ The best estimate for the 2014 version of the survey is $20,000 .{ }^{17}$ As the 2016 WGRA report notes, comparing specific "trends prior to 2014 [is] not possible due to measurement differences." 18

On the topic of comparisons, the 2018 report indicates that "survey methodology used on WGR surveys has remained largely consistent across time, which allows for comparisons across

\footnotetext{
${ }^{14}$ Protect Our Defenders, Debunking Claims of Progress on Military Sexual Assault (Nov. 2015), https://www.protectourdefenders.com/wp-content/uploads/2013/05/Debunking-Claims-of-Progress.png. ${ }^{15}$ Off. People Analytics, DeP'T DeF., 2018 WorkPlace and Gender Relations SurVey of Active Duty MEMBERS OVERVIEW REPORT 26 (May 2019), https://apps.dtic.mil/sti/pdfs/ad1071721.pdf [hereinafter 2018 WGRA Overview Report].

${ }^{16}$ Off. People Analytics, Dep’t Def., 2016 Workplace and Gender Relations Survey of Active Duty MEMBERS OVERVIEW REPORT 32 (May 2017), https://apps.dtic.mil/sti/pdfs/ad1032638.pdf.

${ }^{17}$ NAT'L Def. Rsch. InSt., Rand CoRP., SeXual Assault and SeXual Harassment IN THE U.S. Military: ToPLiNE ESTIMATES FOR ACTIVE-DUTY SERVICE MEMBERS FROM THE 2014 RAND MILITARY WORKPLACE STUDY 9 (2014), https://www.rand.org/content/dam/rand/pubs/research reports/rr800/rr870/rand_RR870.pdf.

${ }^{18} 2016$ WGRA OVERVIEW REPORT, supra note 16 at ix.
} 
survey administrations." ${ }^{19}$ These two separate methodological observations suggest that the reports from 2014, 2016, and 2018 allow for fairly useful specific trend comparisons, while reports prior to this are decidedly less useful as a comparison set for current trends. With the estimated prevalence statistics bracketed in this manner, then, the top-line prevalence estimates for 2014, 2016, and 2018 is $20,000,14,900$, and 20,500 , respectively.

\section{Identifying the WGRA Survey Population}

With these reflections on similar methodology and the comparative trend in focus, how are these estimates derived, and what are some of the limitations inherent in relying on the estimates as a primary justification for major policy reform? For ease of reference, the present analysis focuses primarily on the methodology for the 2018 WGRA survey - though there are some marginal methodological divergences that have been incorporated as the survey administrators have finetuned the process over time. ${ }^{20}$

The first point of interest to note regarding the 2018 WGRA survey is that out of a total eligible population of 1,285,990 active-duty DoD servicemembers in the paygrades of E1 to O6, the sample size of the survey - the amount of the eligible population to which the voluntary survey is made available - was 694,441 servicemembers. ${ }^{21}$ This sample size amounts to $54 \%$ of the eligible active-duty DoD population. Out of this sample of potential participants, responses were received from 102,109 service members. Because the response rate is adjusted slightly in an attempt to mitigate the effects of a statistical bias that can be introduced when members of smaller population categories in the sample set decline to participate in the survey, the response rate is weighted using a formula that is summarized in a graph presented in the report. ${ }^{22}$

In any event, the survey report adjusts the "raw" response rate from 14.7\% (102,109 divided by 694,441$)$ to a total weighted response rate of $17 \%$. This adjustment means the total weighted number of responses, for purposes of the survey, is 118,055 rather than the actual number of responses $-102,109$. Nonetheless, even with this higher weighted number of responses, the total (weighted) response rate if the number of responses is applied to the entire eligible active-duty DoD population is just $9 \%$, while the unweighted response rate when applied to the entire eligible

\footnotetext{
192018 WGRA OVERVIEW REPORT, supra note 15 at 15.

${ }^{20}$ See id. at 5.

${ }^{21}$ Id. at 19.

${ }^{22}$ See id. (Figure 10).
} 
population is slightly lower, at $7.9 \%$. Because the variance between the two rates is minimal and the survey findings are based on the weighted response rate, the present analysis adopts the higher response rate of $9 \%$, when applied to the total eligible population, as well.

It is of course common practice for survey reports to extrapolate statistical analyzes and present generalized findings that apply to an entire population based on responses that are received from a small fraction of the measured population. However, any such study must account for and try to mitigate the effects of statistical bias, or any factor "that leads to a systematic difference between the true parameters of a population and the statistics used to estimate those parameters."23 Any existing bias that is introduced will propagate throughout the statistical calculations as the findings from the response set are extrapolated to apply to the entire population set. ${ }^{24}$

At a total (weighted) response rate of only $9 \%$ when applied to the total eligible population, the possible effect of propagation error introduced from any potential statistical bias can be quite significant. The relatively low response rate is a limiting factor the report authors acknowledge and suggest that OPA is "undertaking a number of efforts to improve the gradually declining response rates" for the survey. ${ }^{25}$ Thankfully, the WGRA developers go to impressive lengths to try to mitigate the effect of statistical bias that is introduced into the sample and that propagates throughout the results.

As the next three sections detail, there are several factors that lead the report authors to caution that the WGRA results do not present an estimate of the prevalence of actual sexual assault offenses. These noted limitations certainly do not impugn the findings of the WGRA report. However, the inherent limitations do have significant implications for the accuracy of the estimate as a measure of actual prevalence and for the usefulness of the prevalence statistics derived from the report as a measure of effectiveness upon which to base justifications for major policy reforms.

\section{WGRA Report Limitation: "Behaviors Endorsed By Respondents' Self-Reports"}

The first relevant central limitation acknowledged by the authors of the WGRA report involves the challenge of equating the perception of events conveyed by survey respondents with

\footnotetext{
${ }^{23}$ Jenny Gutbezahl, 5 Types of Statistical Bias to Avoid in Your Analyses, BusINESS INSIGHTS (June 13, 2017), https://online.hbs.edu/blog/post/types-of-statistical-bias.

${ }^{24}$ For a useful overview of the concept of statistical error propagation, see Stephanie Glen, Error Propagation (Propagation of Uncertainty), STATISTICSHOWTO.COM, https://www.statisticshowto.com/error-propagation (last visited July 10, 2021).

${ }^{25} 2018$ WGRA OVERVIEW REPORT, supra note 15 at 19.
} 
experiencing verifiable criminal conduct. The WGRA addresses this limitation by affirming that "all references to 'experiences' of sexual assault ... are based on behaviors endorsed by respondents' self-reports." As such, references to “"sexual assault'... throughout the report do not imply legal definitions." 26

When this limitation is read in conjunction with the estimate that 12,927 women and 7,546 men "experienced a sexual assault in the past 12 months," the caveat that this reference to sexual assault does not imply a legal definition constitutes a significant constraint on the usefulness of this measure as an account of actual incidents of sexual assault in the military. The likelihood that deliberately untruthful survey responses are a factor that could represent a substantial risk of statistical bias is of course minimal, especially in the context of an anonymous survey. However, the fact that the survey relies solely on "behaviors endorsed by respondents' self-reports" to generate statistical data does indicate that the survey results do not present a valid approximation of actual offenses related to sexual assault.

This is so primarily because of the expansive nature of conduct that is defined as "sexual assault" in the military context. An affirmative response indicating that the respondent experienced a penetrative sexual assault in the past year, for example, includes conduct equating to rape pursuant to Article 120 of the Uniform Code of Military Justice (the alleged offender "used, or threatened to use, physical force to make you comply"). However, an affirmative response also can indicate that the penetrative sexual act occurred while the respondent was "so drunk, high, or drugged that you could not understand what was happening or could not show them that you were willing."

This conduct equates to one variety of sexual assault (as opposed to rape) pursuant to Article 120 of the UCMJ. For the former category of sexual misconduct, rape, it is unlikely that an affirmative response on the survey could involve a difference of perceptions as between an alleged perpetrator and a survey respondent. For the latter category, however, the potentially competing perspectives of the participants matters a great deal.

The particular aspect of the crime of the relevant version of sexual assault requires that the victim was incapable of consenting to the sexual act due to impairment and that this "condition is known or reasonably should be known by the" alleged offender. ${ }^{27}$ An affirmative response on the survey accounts for the first aspect of the crime, but not the second. This is to be expected since the

\footnotetext{
${ }^{26} \mathrm{Id}$. at 1.

${ }^{27}$ See 10 U.S.C. $§ 920($ b)(3) (Article 120(b)(3) of the UCMJ) (available at https:/uscode.house.gov/view.xhtml?req=(title:10\%20section:920\%20edition:prelim).
} 
WGRA report is scoped to analyze "behaviors endorsed by the respondents' self-reports" and references to sexual assault "do not imply legal definitions." The potential divergence between perception and genuinely criminal conduct in this context introduces a significant risk of statistical bias as the number of affirmative responses is extrapolated to represent the entire eligible population.

To that end, the confluence of several other factors inherent in the WGRA responses tends to accentuate the risk of statistical bias. While approximately $58 \%$ of the estimated number of respondents who reported experiencing sexual assault were women (estimated 12,927 women compared to estimated 7,546 men), an estimated nearly half (49\%) of affirmative responses by women indicated that a penetrative assault was the most serious behavior they experienced. ${ }^{28}$ Regarding alcohol use, $49 \%$ of women who are estimated to have indicated that they experienced sexual assault also answered that the victim was drinking at the time, while $62 \%$ indicated that the respondent and/or the alleged offender were drinking alcohol during the event. ${ }^{29}$

With women constituting over half of the estimated affirmative responses indicating an experience of sexual assault, and nearly half of these being a penetrative sexual assault, and half or more of all affirmative responses of sexual assault by women involving alcohol consumption, the risk is substantial that the divergence between perception of sexual assault and the crime of sexual assault introduces a statistically significant element of bias. Because the total (weighted) response rate for the survey is only $9 \%$ of the eligible active-duty population, this already statistically significant risk of bias propagates drastically throughout the calculated survey results as the number of affirmative survey responses is adjusted to estimate the prevalence among the entire eligible population.

Lest it seem rather implausible to suggest that such an appreciable gap may exist between perceptions of crime and actual crime, it may be useful to consider that "military training aimed at preventing sexual harassment and assault" has suggested for years that being "barely tipsy" makes a person incapable of consenting to sex. ${ }^{30}$ This is, of course, a gross mischaracterization of the actual

282018 WGRA OVERVIEW REPORT, supra note 15 at 30.

${ }^{29}$ Id. at 33 .

${ }^{30}$ Nancy Montgomery, US Military Court Addresses 'Incapable of Consent' to Sex Issue, STARS AND STRIPES (May 17, 2016), https://www.stripes.com/news/us-military-court-addresses-incapable-of-consent-to-sex-issue-1.409974. It should be noted that this report does not constitute official DoD guidance. Though anecdotal, my own experience with receiving sexual assault prevention and response training during the course of my military career is consistent with this observation, and I assess that many servicemembers would endorse a similar experience. Partially as a result of this misinformation that is (or, at least used to be) communicated during standard prevention and response 
legal standard. Military training involving the prevention of sexual assault has long been recognized in the ranks as inadequate, ${ }^{31}$ and recent efforts have focused on improving this deficiency. ${ }^{32}$

Nonetheless, current shortcomings in military sexual assault response and prevention training generate a significant degree of confusion regarding what sexual assault is - and as importantly - is not. Even absent this confusion, cases involving an allegation that the defendant engaged in sexual activity with a person who was incapable of consenting due to alcohol intoxication are among the most difficult alleged offenses for a trier of fact to adjudicate. ${ }^{33}$ As mentioned above, this is because a guilty verdict requires a finding, to a standard of beyond a reasonable doubt, that the alleged assailant knew or reasonably should have known that the other person was incapable of consenting - and such a finding often turns on circumstantial evidence and evaluating competing perceptions.

One recent study of sexual assault in the military summarizes some of the challenges with perceptions in such cases by describing that a "person who consumes alcohol to a blacked-out state may not remember how much alcohol they consumed or they may engage in conduct that could cause another to reasonably believe consent exists for sexual intercourse, and afterwards he or she would have no recollection of their conduct." 34 Given that a separate report examining the same time period as the 2018 WGRA survey estimated that more than a third of service members were current binge drinkers ${ }^{35}$ and found that "risky sexual behavior among service members was not uncommon," ${ }^{36}$ it is certainly possible that a connection between alcohol and sexual behavior has an effect on "behaviors endorsed by respondents' self-reports," which the WGRA report analyzes. This

training, I developed my own customized prevention and response training to present to the soldiers in my unit when I served as a brigade judge advocate just prior to retiring from the military.

${ }^{31}$ See, e.g., Haley Britzky, This Army Unit Will Now Immediately Start Separating Soldiers Found Guilty of Assault or Harassment, TASK AND PURPOSE (May 10, 2021), https://taskandpurpose.com/news/18th-airborne-corps-sexualharassment-assault (reporting on efforts to improve prevention and response training and concluding with a quote from a soldier who indicated, "I'm just saying what I feel and what I know so many other people feel ... like, the SHARP [sexual harassment and assault response and prevention] training is not effective").

32 See Sarah Blake Morgan, US Army Crowdsources Ideas to Combat Sexual Assault Crisis, AssociATED PRESS (Feb. 26, 2021), https://apnews.com/article/army-crowdsource-combat-sexual-assault$4 \mathrm{~b} 622 \mathrm{cb} 4 \mathrm{c} 2 \mathrm{e} 842 \mathrm{ffd} 8 \mathrm{~d} 074 \mathrm{ec} 932 \mathrm{edf} 83$.

${ }^{33}$ See, e.g., U.S. v. Pease, NMCCA 201400165 (Navy \& Marine Corps Crim. App. July 14, 2015) (available at https://www.jag.navy.mil/courts/documents/archive/2015/pease-201400165-pub.pdf), aff'd, C.A.A.F. No. 16-0014 (Mar. 17, 2016) (available at https://www.armfor.uscourts.gov/newcaaf/opinions/2015SepTerm/160014.pdf). ${ }^{34}$ David A. Schlueter \& Lisa M. Schenck, National, Military, and College Reports on Prosecution of Sexual Assaults and Victims' Rights: Is the Military Actually Safer than Civilian Society?, 56 GoNZ. L.R. 285, 345 (2021).

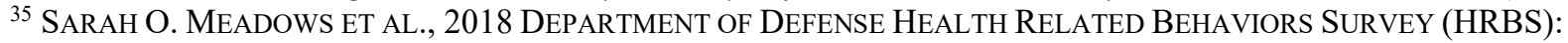
RESULTS FOR THE ACTIVE COMPONENT, RAND CORP. 204 (2021), https://www.rand.org/pubs/research_reports/rr4222.html.

${ }^{36} I d$. at 207. 
finding is consistent with the WGRA report, which, as mentioned above, identifies a significant connection between alcohol use and what the survey describes as an "unwanted [sexual] event." 37

In short, the incredible degree of nuance associated with sexual conduct for which alcohol is a factor means that there may be a considerable gap between perceptions of an assault and the crime of assault for certain types of sexual assault that can be difficult to account for in a statistical analysis of survey responses. The same is true for the non-penetrative offense of abusive sexual contact, incidentally, which requires a finding that the alleged offender touched another person on a "private" part (to summarize the list of body parts) with the intent to abuse, humiliate, harass, or degrade the victim or to do so for the purpose of sexual gratification. Though alcohol is not necessarily as much of a factor in parsing perception from offense for abusive sexual contact as it can be for the offense of sexual assault when alcohol is involved in the latter, both of these types of offenses involve a significant degree of perception that is difficult to account for on a survey that measures experiences of sexual assault that are based on behaviors endorsed by respondents' selfreports.

The resultant significant risk of statistical bias that propagates as the number of affirmative survey responses is expanded to generate an estimate of prevalence across the entire eligible survey population, of course, does not impugn the findings of the WGRA findings. The validity of the findings is not impugned because the report affirms that "all references to 'experiences' of sexual assault ... are based on behaviors endorsed by respondents' self-reports" and that references to “"sexual assault'... throughout the report do not imply legal definitions." 38 However, relying on "behaviors endorsed by respondents' self-reports" without being able to develop additional information regarding the self-reports does substantially limit the usefulness of the prevalence statistics reflected therein as a measure of the effectiveness of the military justice system to adjudicate crimes of sexual assault.

\section{WGRA Report Limitation: "Unique Military Context”}

A second central limitation in the prevalence statistics presented in the WGRA report involves what the authors describe as the "unique military context" that may set the findings apart from other studies that address a non-military setting. As the authors of the WGRA report note,

372018 WGRA OVERVIEW REPORT, supra note 15 at 33.

${ }^{38} I d$. at 1 . 
such "differences may manifest in terms of both victimization and perpetration." 39 According to the authors, this characteristic "motivates the need to collect data specific to the military population regarding not only the prevalence of sexual assault but also the characteristics of these incidents, including the individual, social, organizational, or environmental factors that may prevent or support them." 40

Among these latter noted aspects, the "organizational" factor of the "unique military context" involved in the WGRA report is particularly prone to the prospect of introducing statistical bias that can be propagated as the survey responses are expanded to derive an estimated prevalence from among the entire eligible population. To that end, a recently published study ${ }^{41}$ examining the 2018 WGRA results suggests that "sexual assault risk is associated with individual characteristics of members of the military and aspects of military service, such as service branch, occupation, and unit characteristics." 42 A similar finding from this recent report likewise suggests that "lower sociocultural and organizational power are associated with increased likelihood of experiencing

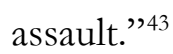

The inability of the WGRA report to incorporate a mechanism to account for the "unique military context" such as "individual, social, organizational, or environmental factors" introduces yet another potential source of statistical bias. Yet again, this limitation does not necessarily impugn the findings of the WGRA report since it does not purport to present an accurate estimate of the prevalence of actual sexual assault offenses. However, the risk for propagation of statistical bias does exist since the survey doesn't account for such "unique military context" when the survey responses are expanded to provide an estimate of prevalence from among the entire eligible military population. This limitation indicates that the WGRA report is not a particularly accurate measure for actual prevalence across the U.S. military population as a whole.

\footnotetext{
${ }^{39} I d$. at 25 .

${ }^{40} I d$.

${ }^{41}$ For a useful overview of the report, see Jennifer Steinhauer, A New Report Shows that the Risk of Sexual Assault for Women in the Army Is Highest at Fort Hood, N.Y. TIMES (June 18, 2021), https:/www.nytimes.com/2021/06/18/us/politics/military-sexual-assault.html

42 Miriam Matthews ET Al., ORganizATIONAl CHARACTERISTICS ASSOCIATED With RiSK OF SEXUAL ASSAULt AND SEXUAL HARASSMENT IN THE U.S. ARMY, RAND CORP. 3 (2021), https://www.rand.org/pubs/research_reports/rra1013-1.html.

${ }^{43} I d$. at 4.
} 


\section{WGRA Report Limitation: Non-Response Bias}

A final potential limitation regarding the WGRA report as a useful measure of the performance of the U.S. military justice system is that the survey methodology and fairly low response rate introduce the possibility for non-response bias. In this context, "non-response bias" can be summarized as a statistical distortion that occurs when certain groups are more inclined to participate in the survey than other groups in the population. ${ }^{44}$ Professors David Schlueter and Lisa Schenck raise this concern with the WGRA findings in a recent paper by suggesting that a person who has experienced sexual assault may be "more likely to complete the lengthy WGRA written survey than a person who has not been sexually assaulted, which may inflate the number of sexual assault victims." 45 Indeed, a 2017 study of estimated sexual assault prevalence in the Canadian military found that "members who had experienced sexual assault may have been more likely to respond [to the online survey] than members who had not experienced sexual assault" and that this introduced the risk of statistical bias in the survey results. ${ }^{46}$

In the context of the WGRA, the report authors do indicate that the OPA uses a "variety of methods to gauge potential non-response bias" and "has found no evidence of non-response bias." 47 However, it is difficult to assess the effectiveness of such control measures since the report authors do not provide details regarding the methods employed. Likewise, it is not clear whether the "variety of dimensions" for non-response bias that are evaluated by the report authors include the possibility that a person who has experienced sexual assault is more likely to take the time and effort necessary to respond to the survey.

For what it may be worth, my own experience with WGRA surveys (and their predecessors) while I was in the military is consistent with the concerns expressed by Professors Schlueter and Schenck and that are expressed in the survey related to sexual assault prevalence in the Canadian Armed Forces mentioned above. Despite receiving multiple invitations to participate in the survey during numerous successive years, not once did I elect to participate in the survey. My own

\footnotetext{
${ }^{44}$ For a useful summary of the statistical concept, see Stephanie Glen, Non Response Bias: Definition, Examples, STATISTICSHOWTO.COM (Oct. 11, 2015), https://www.statisticshowto.com/non-response-bias.

${ }^{45}$ David A. Schlueter \& Lisa M. Schenck, A White Paper on National, Military, and College Reports on Prosecution of Sexual Assaults and Victims' Rights at 9 (July 2020), https://www.caaflog.org/uploads/1/3/2/3/132385649/us_military_v._college_paper_july_21_pdf.

${ }^{46}$ Kimberley Watkins et al., Military-related Sexual Assault in Canada: A Cross-sectional Survey, 5 CMAJ OPEN E496, E501 (2017), https://www.cmajopen.ca/content/cmajo/5/2/E496.full.pdf.

472018 WGRA OVERVIEW REPORT, supra note 15 at 322.
} 
declination was based on the incorrect perception that I would have nothing substantial to contribute to the survey if I participated.

At the earliest such invitation that I recall, which was for the 2010 version of the survey, it had been well over a decade since I had personally experienced sexual assault in the military. Based on my own personal circumstances, I was able to cope with that experience fairly well and had long since moved on. It was not clear to me that I would have anything worthy of contributing for a survey involving sexual assault (among other topics) in the military. This experience - declining to participate in the survey based on a misperception that I would have nothing substantial to contribute - was prevalent among my friends and coworkers, too, whether or not they expressed that they had any personal experience with sexual assault in the past.

While these reflections are, of course, purely anecdotal, my own recollections regarding the WGRA survey support the concerns related to non-response bias that have been expressed elsewhere in the literature. Again, this may be a factor that is adequately addressed by the authors of the WGRA report, but it is difficult to assess the effectiveness of any control measures since the methods are not disclosed, nor are the specific "variety of dimensions" for which the authors attempt to control. In any event, the potential that non-response bias may skew the results reflected in the WGRA report detracts from the utility of the results as an expression of actual sexual assault prevalence and as a gauge of the effectiveness of the U.S. military justice system writ large.

\section{The Way Ahead with WGRA Statistics Situated in the Proper Context}

With these three significant limitations in mind, I close by assessing the landscape of the current debate regarding military justice reform if the WGRA report is positioned in the proper context. Given that the WGRA findings provide only an estimate of reported experiences related to sexual assault (among other topics) rather than actual crimes of sexual assault, how useful is the report as a gauge of the effectiveness of the U.S. military justice system in responding to allegations of sexual assault? In short, the WGRA survey reports are of extremely limited probative value as a measure of the effectiveness of the military justice system. This is true regardless of whether disposition authority for sexual assault offenses is vested in commanders or military lawyers.

The value as a measure of the effectiveness of the military justice system in the effort to prevent and respond to sexual assault offenses is limited primarily for three reasons. First, the reports analyze experiences respondents endorse in answering surveys rather than actual criminal 
offenses - and, of course, the military justice system is only utilized to respond to the latter. Second, even as an analysis of respondents' endorsements of experiences, the risk of statistical bias examined above means the WGRA report does not present a particularly precise estimate. Neither of these factors impugns the analysis conducted in the WGRA reports since the authors account for these limitations and therefore do not purport to present a precise estimate of actual offenses.

The third plenary factor that limits the effectiveness of the results of the WGRA report as a measure of the military justice system is that a substantial portion of the estimated number of endorsed experiences of sexual assault in the military involve conduct that very likely would not be referred to a court-martial - whether a commander or judge advocate has that authority. The WGRA report notes that $42 \%$ of women and $60 \%$ of men who endorsed experiencing sexual assault in the year preceding the survey identified a "non-penetrative sexual assault as the worst behavior experienced." 48

While disposition authorities - currently commanders - can refer non-penetrative offenses such as abusive sexual contact to court-martial, for less serious actual offenses of this variety the disposition authority has a number of other disciplinary tools available that can achieve justice. These include measures such as non-judicial punishment and an administrative separation (that is, terminating the military service of the offender) with a potentially other-than-honorable discharge if the appropriate process is followed. The overall prevalence estimate presented in the WGRA report includes a statistically significant number of endorsed experiences that would quite likely not be referred to court-martial - regardless of who has that authority.

All told, the WGRA survey reports present valuable insights involving trends related to the experiences conveyed by respondents, but the reports provide almost no value as a measure of the military justice system. Although it has been suggested that the estimated prevalence provides a close approximation of the actual number of sexual assaults and this can be compared to the number of reported incidents, ${ }^{49}$ the limitations analyzed in this essay demonstrate that the WGRA reports do not in fact present even a marginally precise estimate of actual offenses. This is completely

\footnotetext{
${ }^{48} \mathrm{Id}$. at 30 .

${ }^{49}$ See, e.g., Landon Allison \& Cassidey Kavathas, Fact-checking Kirsten Gillibrand on Military Sexual Assaults, POLITIFACT (Mar. 25, 2021), https://www.politifact.com/factchecks/2021/mar/25/kirsten-gillibrand/fact-checkingkirsten-gillibrand-military-sexual-a (suggesting that the number of reports of alleged sexual assault actually received by the military chain of command is but "one of two measurements the Pentagon uses to count sexual assaults." The authors continue by surmising, "The other is a biennial estimate of sexual assaults, based on survey responses. The idea is that some servicemembers who are sexually assaulted will not file a formal complaint, but would still be willing to tell a survey taker about it.").
} 
acceptable for the WGRA report since it does not claim to present data regarding actual offenses. The authors of the WGRA report correctly observe that the findings simply help "guide our knowledge" regarding characteristics of sexual assault in the military. ${ }^{50}$

However, using these data as an approximation for actual prevalence or for assessing whether commanders are making sound decisions regarding what alleged offenses to send to trial is not supportable by the methodology or the data. Because the long-running characterization that the U.S. military is beset by an "epidemic of rape" is founded on this fairly consistent estimated prevalence of around 20,000 sexual assaults each year, ${ }^{51}$ lawmakers and the constituents they represent must fundamentally reassess what they have come to believe about the actual prevalence of sexual assault in the military. The same is true for military members, all the way up the ranks.

For example, General Mark Milley, the current Chairman of the Joint Chiefs of Staff, recently observed, "If we had 20,000 casualties in Afghanistan last year or 20,000 casualties in Iraq, we'd be taking some pretty radical actions to correct that." ${ }^{52}$ With a current active-duty military DoD end strength of just under 1.35 million service members, ${ }^{53}$ taking 20,000 casualties would mean losing about $1.5 \%$ of the force in one year. This casualty rate would most assuredly call for "some pretty radical actions."

Likewise, the current prevailing assessment regarding the effectiveness of the military justice system in preventing and responding to sexual assault in the military must be reexamined. To revisit Lynn Rosenthal's assertion, for example, that "twenty thousand service members experience sexual assault every year" while "only a tiny fraction of those end up with any kind of action at all in the military justice system," 54 there is actually very little connection between the estimated prevalence and the performance of the military justice system.

To develop a more useful sense of the effectiveness of commanders when deciding whether to refer an alleged sexual offense to trial, a much more specific study would need to be undertaken than the WGRA reports present. Fortunately, several such studies have been conducted. The most

\footnotetext{
${ }^{50} 2018$ WGRA OVERVIEW REPORT, supra note 15 at 25.

${ }^{51}$ See, e.g., John M. Donnelly, Lawmakers Near Big Response to Military 'Rape Epidemic', Roll CALl (Feb. 4, 2021), https://www.rollcall.com/2021/02/04/lawmakers-near-big-response-to-military-rape-epidemic (quoting Don Christensen, president of the advocacy group Protect Our Defenders, who reportedly referred to an "epidemic of rape" in the military and observed that "[t]here are an estimated 20,500 military men and women sexually assaulted in a year, yet barely 100 offenders are convicted").

52 Oren Liebermann, Top US General Drops Opposition to Major Policy Changes on Sexual Assault in the Military, CNN (May 3, 2021), https://www.cnn.com/2021/05/03/politics/milley-sexual-assault-military/index.html.

${ }_{53}^{53}$ Armed Forces Strength Figures for May 31, 2021, supra note 8.

${ }^{54}$ See Dep't. Def. Press Briefing, supra note 11.
} 
recent such study determined that "there is not a systemic problem with the initial disposition authority's decision either to prefer a penetrative sexual offense charge or to take no action against the subject for that offense." ${ }^{55}$ This study, published in October 2020 by the Defense Advisory Committee on Investigation, Prosecution, and Defense of Sexual Assault in the Armed Forces, analyzed actual casefiles that were initially considered by commanders. The authors of the report concluded that "in $94.0 \%$ and $98.5 \%$ of cases reviewed, respectively, those decisions [by commanders] were reasonable." 56

Whatever the path ahead may be for the ongoing debate regarding commander disposition authority and sexual assault in the military, ${ }^{57}$ those engaged in the discussion must remain cognizant of the fact that the central problem they seek to address - the "epidemic of rape and sexual assault" in the military - is not in fact supported by the prevalence data that is so often cited in favor of this characterization. Likewise, the denominator - 20,000 - for the "tiny fraction" of cases that commanders send to trial in no way reflects actual sexual assault offenses. In whatever manner the debate plays out, those in a position to make decisions will if nothing else be better informed with this essential knowledge.

\footnotetext{
${ }^{55}$ Defense Advisory Committee on Investigation, Prosecution, and Defense of SeXual Assault in the Armed Forces, Report On Investigative Case File Reviews For Military Adult Penetrative SeXual OFFENSE CASES CLOSED IN FISCAL YEAR 2017 at 15 (Oct. 2020), https://dacipad.whs.mil/images/Public/08Reports/08_DACIPAD_CaseReview_Report_20201019_Final_Web.pdf.

${ }^{56} \mathrm{Id}$. at 3 .

${ }^{57}$ For a summary of recent developments on the topic, see Jennifer Steinhauer, Pushing Beyond Sex Assault, Gillibrand Faces Resistance to Military Bill, N.Y. Times (July 14, 2021), https://www.nytimes.com/2021/07/14/us/politics/sexual-assault-military-felonies.html.
} 